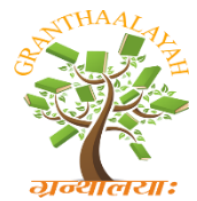

\author{
INTERNATIONAL JOURNAL OF RE
GRANTHAALAYAH \\ A knowledge Repository
}

Science

\title{
STUDY OF URINARY SYSTEM CALCULI IN SUDANESE USING COMPUTED TOMOGRAPHY 2018-2019
}

\author{
Maha Esmeal Ahmed ${ }^{1}$, Mwahib Sid Ahmed Aldosh ${ }^{2}$ \\ ${ }^{1} \mathrm{Ph}$. D, Associate Professor, Radiography and Medical Imaging Sciences, Radiological Sciences \\ College, National University- Sudan \\ ${ }^{2} \mathrm{Ph}$. D, Associate Professor, Applied Medical College, Radiological Sciences Department, \\ Najran University- Kingdom of Saudi Arabia
}

\begin{abstract}
Objective: The aim of study was to study the chemical composition of renal stone in Sudanese population using computed tomography scan.

Method: This is analytic study conducted in Khartoum state hospitals in the period from November 2018 to October 2019. The problem of the study was no similar study done in Sudanese populations. The study was done in 100 patients. The data was collected from computed tomography scan to the kidneys, ureters and urinary bladder. Classified and analyzed by statistical package for the social sciences application (SPSS).

Results: The study found that most chemical composition of renal stone among Sudanese population was uric acid (0\%), Cystine (26\%) then Struvite (14\%) and calcium (60\%). The most effective age group with renal stone was (61-70) years old (36.7\%) and same age group have a Struvite stone $(28.3 \%)$. Furthermore, the most common age group with a cyctine renal stone were the cystine affect in the age between 50 years to 60 years old.

The uric acid, Cystine, and calcium stone composition may be reliably predicted in vivo on the basis of dual-energy Computed tomography findings. In the future, a single dual-energy computed tomography examination may contribute to not only the identification but also the chemical characterization of stones in the urinary tract and it may add to the information available from nonenhanced conventional CT performed for evaluation of nephrolithiasis.
\end{abstract}

Keywords: Renal Stone; Stone Type; Computed Tomography.

Cite This Article: Maha Esmeal Ahmed, and Mwahib Sid Ahmed Aldosh. (2019). "STUDY OF URINARY SYSTEM CALCULI IN SUDANESE USING COMPUTED TOMOGRAPHY 20182019." International Journal of Research - Granthaalayah, 7(10), 233-237. https://doi.org/10.29121/granthaalayah.v7.i10.2019.391.

\section{Introduction}

Urinary tract stones are common, with a lifetime incidence of up to $12 \%$ and recurrence rates of up to $50 \%$. In diagnostic and treatment algorithms, stone burden is the most important factor to 
consider and forms the basis of all clinical decision making (1) Thus, accurate measurement of all calculi is crucial. Since its introduction (2). Unenhanced helical computed tomography (CT) has replaced intravenous urogram and is now regarded as the reference standard in the work-up of renal colic, owing to its high sensitivity and specificity. Apart from being the diagnostic standard, CT has the advantage of providing detailed anatomical information, can identify secondary signs. of stone passage and is useful for ruling out alternate pathologies in cases of diagnostic uncertainty. Despite the advantages of unenhanced CT, ultrasound is also commonly used as a diagnostic tool in the management of urolithiasis. US is recognized to be both less sensitive and specific than CT; however, it is commonly available, inexpensive to operate and poses no risk of radiation exposure. In many cases, renal and ureteric calculi are incidentally diagnosed in the workup of other conditions. It has been reported that may detect stones as small as $0.5 \mathrm{~mm}$ under optimal conditions. For these reasons, some centers may still use in the initial work-up of renal colic (3)

Up to date, there has been little direct comparison of the accuracy and reliability of US compared with CT in sudan. Non-contrast spiral CT is presently more extensively used for the diagnosis of urolithiasis, especially in the setting of acute flank pain in adult patients. However, there is little data published over the use of spiral CT in pediatric urolithiasis $(4,5,6)$. The presenting symptoms of children with stone disease are neither characteristic nor predictable and range from none to sepsis. Thus in pediatric patients with signs and symptoms suggestive of stone disease, radiologic studies are necessary for making an accurate diagnosis. Classically kidney, ureter and bladder plain films (KUB). Given that the imaging of stones in children with conventional techniques has generally been non-satisfactory due to problems related to intestinal gas and smaller stone size in children, one may expect that spiral CT would be very beneficial for this age group. (7)

The CT images were conducted using (TOSHIBA aquilion 64 slices) CT scanner. The scan parameter ( $3 \mathrm{~mm}$ slice, $120 \mathrm{kvp}, 225 \mathrm{MAS})$. And with using the electronic caliper within the scanner the following diameters were measured. The features of CT scanner are 256 slices in one rotation with $0.5 \mathrm{~mm}$ slice thickness Coverage of $13 \mathrm{~cm}$ in patient axis direction Advanced Sure Workflow software with PhaseXact Largest couch capacity in the industry $-180 \mathrm{~cm}$ long by $47 \mathrm{~cm}$ wide $40 \%$ dose reduction compared to previous models (8) CT KUB (non-contrast enhanced CT of kidney, ureter and bladder) is useful to determine the number and location of urinary tract calculi. It is used in some centers as primary investigation of renal calculi. The patient lies supine on CT scanner table. Scout view was obtained. A low radiation dose technique is used to scan from the top of the kidney to include the bladder base with slice thickness of $5 \mathrm{~mm}$ or less as determine by CT saner (no use of i.v. contrast) $(9,10)$.

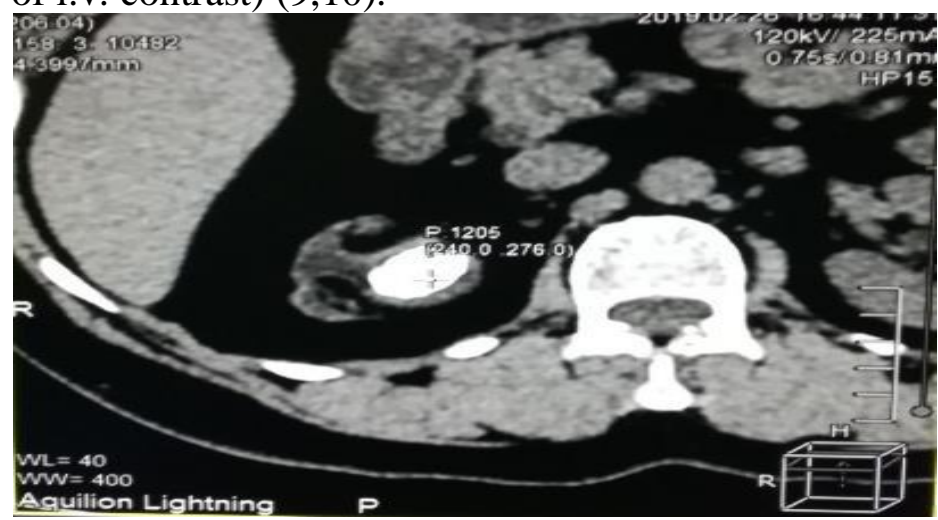

Figure 1: CT -KUB to the patient with bilateral renal stone 


\section{Materials and Methods}

\section{Type and Duration of Study}

A descriptive analytic cross-sectional study done in sudan. Khartoum hospital (zytona hospital_yastabshron) in Khartoum province (Sudan) from november2018 - october 2019

\section{Study Area}

The study conducted at Khartoum state.

\section{Population}

The sample of the study will be 100 patients selected from CT abdomen images for adult in range of age (20-70) years old.

\section{Sample Size}

Sample size was (100) cases selected prospectively of patient with urinary tract stones

\section{Variables of the Study}

Patient gender, Age, History of disease, Sign, symptoms and site of stone.

\section{Inclusion Criteria}

The study will include all patients with flank pain at age between (20-70 years), female or male collected data will include patient data (age - gender_ weigth)

\section{Exclusion Criteria}

All patients with Allergy to contrast agent, Pregnancy, Renal insufficiency, was excluded from this study. and patients less than 20 years old and more than 70 years old.

\section{Methods of Data Analysis}

The data analyzed using SPSS program.

\section{Ethical Approval}

Ethical approval has been granted from the hospital and the department of radiology this did not include or disclose any [ID] information concerning the patient. Informed consent was obtained from all individual participants; included in the study.

\section{Result}

Table 1: Gender of patients

\begin{tabular}{|l|c|c|c|c|}
\hline & Frequency & Percent & Valid Percent & Cumulative Percent \\
\hline male & 82 & 82 & 82 & 82 \\
\hline female & 18 & 18 & 18 & 100 \\
\hline total & 100 & 100 & 100 & \\
\hline
\end{tabular}


Table 2: Stone location

\begin{tabular}{|l|c|c|c|c|}
\hline & Frequency & Percent & Valid Percent & Cumulative Percent \\
\hline Kidney & 70 & 70 & 70 & 70 \\
\hline ureter & 17 & 17 & 17 & 87 \\
\hline Urinary bladder & 13 & 13 & 13 & 100 \\
\hline total & 100 & 100 & 100 & \\
\hline
\end{tabular}

Table 3: Types of stone according to the chemical composition

\begin{tabular}{|l|c|c|c|c|}
\hline & Frequency & Percentage & Valid Percentage & Cumulative Percentage \\
\hline Uric acid & 0 & 0 & 0 & 0 \\
\hline Calcium & 60 & 60 & 60 & 60 \\
\hline Cysteine & 26 & 26 & 26 & 86 \\
\hline struvite & 14 & 14 & 14 & 100 \\
\hline Total & 100 & 100 & 100 & \\
\hline
\end{tabular}

\section{Discussion}

In this study the patient are 100 patients 18 of them are female which is represent (18\%) while the males are 82 which is (82\%), According to the type of study all of them are CT-KUB (table (1). All CT-KUB scan diagnosed with stone in different sites in collecting system of urinary system, $(70.0 \%)$ of all cases the stones found in kidney while another $(17 \%)$ the stones found in ureter and $(13.0 \%)$ the stones found in urinary bladder .(table 2) And the most chemical composition of stones are calcium which represent $(60.0 \%)$ of all collected data. All cases in this study were selected randomly, radiology department received 60 patients with (the chemical composition as uric acid stone, cystine, (26\%) struvite and (14\%) calcium (60\%) see result (table 3).

\section{Conclusion}

Study of chemical composition of renal stone in Sudanese population using CT scan in two hospitals in Khartoum state, period from November 2018 to October 2019 , according to the small number of data for CT-KUB scan show a significant result and great predict to diagnose type of chemical composition of renal stone. This study found most chemical composition of renal stone among Sudanese population is uric acid, cystine then struvite and calcium. The most patients with calcium of renal stone in khartoum were cystine, (26\%) struvite and (14\%) calcium (60\%).

\section{References}

[1] Teichman JM. Clinical practice. Acute renal colic from ureteral calculus. N Engl J Med. 2004; 350:684-693.

[2] Smith RC, Rosenfield AT, Choe KA, et al. Acute flank pain:comparison of non-contrast-enhanced CT and intravenous urography. Radiology. 1995; 194:789-794.

[3] Smergel E., Greenberg S.B., Crisci K.L., Salven J.K.: CT urograms in pediatric patients with ureteral calculi: do adult criteria work? Pediatr Radiol, 2001, 31: 720-723.

[4] S. Oner, A. Oto, S. Tekgul, M. Koroglu, M. Hascicek, A. Sahin and O. Akhan,Comparison of Spiral CT and us in the evaluation of pediatric urolithiasis , JBR-BTR, 2004, 87: 219-223 
[5] Strouse P.J., Bates D.G., Bloom D.A., Goodsitt M.M.: Non-contrast thin section helical CT of urinary tract calculi in children. Pediatr Radiol, 2002, 32: 326-332.

[6] Niall O., Russell J., MacGregor R., Duncan H., Mullins J.: A comparison of noncontrast computerized tomography with excretory urography in the assessment of acute flank pain. J Urol, 1999, 161: 534-537

[7] Graaff, Van De (2002). "Human Anatomy, Sixth Edition". New York: McGraw-Hill.

[8] Mader, Sylvia S. (2004). Human Biology. New York: McGraw-Hill.

[9] Smith, Peter (1998). Internet reference, The Role of the Kidney. Department of Clinical Dental Sciences, The University of Liverpool.

[10] McCance, Katherine L., Heuther, Sue E. (1994). "Pathophysiology: The Biological Basis for Disease In Adults and Children, Second Edition". Mosby-Year Book, Inc. (Robbins 2007).

*Corresponding author.

E-mail address: maha_esmeal@yahoo.com 